\title{
Ambiguity Aversion among Student Subjects: The Role of Probability Interval and Emotional Parameters
}

\author{
Mahmud Yesuf and Robert M. Feinberg \\ Department of Economics \\ American University
}

July 2013

\begin{abstract}
We study risk and ambiguity aversion among experimental subjects, focusing on understanding the role of the degree of ambiguity (as measured by the probability interval) and selected emotional parameters on attitudes towards ambiguity. In contrast to the general findings in the literature that people usually tend to take gambles with known probability over equivalent gambles with ambiguous probability, we find that student subjects are ambiguity neutral when faced with a relatively narrow probability interval but ambiguity averse in relatively wider intervals. We also find that less trusting and more pessimistic individuals tend to avoid ambiguity, while a measure of subject happiness has no impact on ambiguity aversion.
\end{abstract}




\section{Introduction}

In the literature on decision-making under uncertainty, it has been shown that decision makers tend to prefer taking gambles with known-risk probabilities (pure risk) over equivalent gambles with ambiguous probabilities (e.g., Camerer and Weber (1992), Chow and Sarin (2002),

Fox and Tversky (1995)' Heath and Tversky (1991), Viscusi and Chesson (1999), Viscusi and Magat (1992) and Zeckhauser (2006)). In Ellsberg's (1961) simple illustration of the issue, two urns are filled with red and black balls, Urn A containing 50 red and 50 black balls, and Urn B containing an unknown ratio of 100 red and black balls, randomly chosen. A decision-maker chooses a color (red or black) and an urn (A or B) from which to make a blind drawing and wins a prize if a ball of the chosen color is drawn. A large majority of decision-makers strictly prefer the known-risk Urn A to the ambiguous Urn B, irrespective of the preferred color. Such ambiguity aversion has also been found in many applied contexts, including insurance decisions (Einhorn and Hogarth (1985; 1986)), environmental risk (Viscusi et al. (1991), Alpizer et al. (2010), Dalton and Yesuf (2011)), and medical decisions (Ritov and Baron (1990)).

In the context of randomized field experiments, ambiguity is commonly framed by either providing the participants with ranges of probabilities (e.g., Cohen et al. 1985)) or by providing them with conflicting probabilistic estimates (e.g., Hogarth and Kunreuther (1985), Viscusi and Chesson (1999)). A probability interval is perhaps the most common form of operationalizing ambiguity experiments (Budescu et al. (2002)), however generally ambiguity experiments are conducted using a single probability interval. The response to variations in the degree of ambiguity (via a change in the probability interval) on ambiguity aversion is not clearly 
understood in the literature. Another important dimension that is not properly treated in the literature is the role of emotional and psychological factors (such as degree of pessimism or optimism, trust, and happiness) in the response to ambiguity.

The goals of this study are to jointly investigate risk and ambiguity aversion among student subjects at American University and to attempt to understand the role of emotional factors and relative probability intervals on their responses. The rest of the paper is organized as follows. Our experimental design is explained in Section 2. The data analysis and main results are shown in Section 3, and Section 4 provides some concluding remarks.

\section{Experimental design and procedure}

The experiment was conducted on 20 randomly selected freshmen students at American University in Washington D.C. in two rounds in Spring 2013. ${ }^{1}$ We employed a choice listing to elicit subjects' certainty equivalent for risky and ambiguous prospects, where each subject was given a list to choose between a given prospect and a certain amount of sure money. Four different treatments (games) were used to elicit risk and ambiguity aversion, and test for the equivalence of ambiguity aversion with small and large probability intervals. Two of the treatments were risky prospects and the other two were ambiguous prospects. In game 1, subjects were asked to choose between playing a gamble with a $90 \%$ chance of winning $\$ 40$ and $10 \%$ chance of winning nothing, or just receiving a certain amount of money This risky prospect was demonstrated using 9 white chips and 1 black chip in a cup. They were told that they could choose this prospect and win $\$ 40$ if they pick the white chip or nothing if they pick the black chip, or walk out with a certain amount of sure money. In game 2 subjects were asked to choose between playing a gamble with between 80 and 100\% chance of winning $\$ 40$ and between a zero

\footnotetext{
${ }^{1}$ We expect to conduct experiments doubling the sample size in the Fall of 2013.
} 
and $20 \%$ chance of winning nothing, or just receiving a certain amount of money. Game 2 was identical to game 1 except the proportion of colors in the ambiguity cup is unknown. It could either be 8,9 or 10 white chips and 0 or 1 , or 2 black chips. The exact combinations of chips in the cup was determined later through random draw in front of each student subject after they made their decisions. Game 3 was similar to game 1 except the winning probability was $75 \%$ and losing probability was $25 \%$, and winning sum was $\$ 48$. This was demonstrated using 5 black and 15 white chips in a cup. Again subjects were asked to choose between this prospect and a certain amount of sure money. Game 4 was identical to game 3 except that the exact combination of white and black chips in the cup was unknown. Any combination from 0-10 black and 10-20 white chips was possible. Again, the exact combination was determined using a random drawn in front of each student subject later after they made their decisions. Each game was designed with a list of seven choices and, overall, each subject made 28 choices. Once they completed all their choices, we put 28 numbered draws in a bag and asked the players to pick one to determine which choice would be played for real money. The experiment was explained both orally, in writing, and with the aid of power point presentations for all participants. In order to minimize potential anchoring effects, there was a ten minute break between games 1 and 2, and games 3 and 4 .

After subjects made their choices in each ambiguity game (but before the true risks were revealed), subjects were asked to indicate their best a priori guess of the combinations of black and white chips that would be in the cup. This was later used in the analysis as a measure of subjects' degree of pessimism and optimism. At the end of the experiment, subjects were also asked to state their level of trust and happiness via a set of standard structured questions. The 
overall experiment took about 45 minutes. On the average each student subject won a total of $\$ 45$ (\$35 from the game and \$10 from show up fee). Students seemed motivated and we believe that these compensations had given the student subjects to take the experiment seriously and reveal their true preferences. The complete experimental framework is presented in the appendix.

\section{Experimental Results}

\section{Ambiguity aversion and the probability interval}

Our risky and ambiguous prospects are identical in terms of their expected values when the ambiguous prospect is evaluated at the midpoint of the probability interval. If the subject is indifferent between playing a gamble and taking a specific sum of sure money in a risky prospect, she should be indifferent to the same proposal in the ambiguous prospect, in the absence of ambiguity aversion. Thiswould imply identical certainty equivalents for both options. ${ }^{2}$ A lower certainty equivalent in game 2 than game 1 or game 4 than game 3 is a pure indicator of ambiguity aversion. Furthermore, games 2 and 4 are both ambiguity games, and have equivalent expected values though they are different in terms of ambiguity interval. Game 4 has a wider probability interval than game 2 . Thus, if the subject is indifferent between playing a gamble and taking a specific sum of sure money in game 2, she might be expected to be indifferent to the same proposal in game 4 . Thus, she should have identical certainty equivalents for both games. A lower certainty equivalent in game 4 than game 2 is an evidence of increased ambiguity aversion with an increased probability interval.

\footnotetext{
${ }^{2}$ A certainty equivalent is simply the amount of money our subjects reveal themselves to be indifferent to the risky outcome with an expected value of $\$ 36$.
} 
Our estimates of CEs of the four games in the experiment are presented in Table 1. The mean CEs in games $1,2,3$, and 4 are $\$ 24.8, \$ 24, \$ 23, \$ 15.75$, respectively, leading to a risk premium of $31.1 \%, 33.3 \%, 36.1 \%$ and $56.3 \%$ respectively. ${ }^{3}$ The standard t-tests indicate that the difference in mean CEs in game 1 and 2 is not statistically different from zero (with p-value of 0.73), while a similar test on games 3 and 4 indicates the difference in CEs between games 3 and 4 is statistically different from zero (with p-value of 0.03 ). These test results indicate that the same subjects exhibit different levels of ambiguity aversion depending on the probability interval stated by the experimenter. Our experimental subjects indeed reveal lower CEs (or higher risk premiums) for a relatively wide probability interval than for an equivalent risky prospect (without ambiguity). Furthermore, the CEs for the wider probability-interval ambiguity game (game 4) is smaller than that of narrow interval ambiguity game (game 2), with p-value of $0.02 .^{4}$

Table 1: Mean CEs and Risk Premiums in risk and ambiguity experiments and results of ttests of mean comparisons

\begin{tabular}{|c|c|c|c|c|}
\hline Games & Mean CE & $\begin{array}{c}\text { Risk Premium } \\
(\%)\end{array}$ & $\begin{array}{c}\text { Mean CEs Comparison } \\
\text { Test }\end{array}$ & t-test (P-values) \\
\hline Game 1 (Risky game) & $\$ 24.8$ & $31.1 \%$ & \multirow[b]{2}{*}{ Game $1=$ Game 2} & \multirow[b]{2}{*}{$\mathrm{P}=0.73$} \\
\hline $\begin{array}{lrr}\text { Game } 2 & \text { (Ambiguous } \\
\text { game } & 1, \quad \text { narrow } \\
\text { interval) } & & \\
\end{array}$ & $\$ 24$ & $33.3 \%$ & & \\
\hline $\begin{array}{l}\text { Game } 3 \text { (Risky game } \\
\text { 2) }\end{array}$ & $\$ 23$ & $36.1 \%$ & \multirow[b]{2}{*}{ Game 3 = Game 4} & \multirow[b]{2}{*}{$\mathrm{P}=0.03$} \\
\hline $\begin{array}{l}\text { Game } 4 \text { (Ambiguous } \\
\text { game2, wide interval) }\end{array}$ & $\$ 15.75$ & $56.3 \%$ & & \\
\hline & & & Game $2>$ Game 4 & $\mathrm{P}=0.02$ \\
\hline
\end{tabular}

\footnotetext{
${ }^{3}$ The risk premium is the reduction of the revealed CE below the expected outcome (in all games here, \$36), as a percentage of the expected outcome.

${ }^{4}$ Not reported in Table 1, a comparison of the mean CEs from the two risky games (1 and 3) suggests increased risk aversion in Game 3 (with a lower probability of success but same expected outcome) though the difference is not statistically significant.
} 


\section{The role of trust, happiness, pessimism/optimism on ambiguity aversion}

The role of trust and happiness on ambiguity aversion is analyzed using a regression model, where measures of trust and happiness are included as part of the right hand side variables. We measure trust using a standard question where subjects were asked to indicate their level of trust towards other people (in a scale of 1 to 4 ), where 1 measures that they trust most of the people in their neighborhood and 4 indicates that they don't trust most people in their neighborhood. Happiness was also measured using a similar procedure where subjects were asked to indicate their level of happiness in life (in a scale of 1 to 5) where 1 is very happy and 5 very unhappy. Subjects' degree of pessimism/optimism was directly measured using a follow-up question in ambiguity games where subjects were asked to put their best guess on the combinations of black and white chips in the ambiguity games. We used subjects' stated beliefs on the number of winning chips (white chips) in the ambiguity games as proxies for the measure of degree of pessimism/optimism. Table 2 presents summary statistics on these subject attributes.

Table 2: Basic descriptive statistics of variables

\begin{tabular}{|l|l|l|l|l|}
\hline Variable & Mean & Std. Dev. & Min & Max \\
\hline Age & 18.85 & 0.92 & 18 & 21 \\
\hline Male & 0.4 & 0.49 & 0 & 1 \\
\hline Trust (on a scale of 1 to 4) & 2.2 & 0.88 & 1 & 4 \\
\hline Happiness (on a scale of 1 to 5) & 1.65 & 0.86 & 1 & 4 \\
\hline Optimism (Stated Beliefs, 0 to 100\%) & 74.25 & 12.78 & 50 & 90 \\
\hline
\end{tabular}


Our dependent variable in the regression model is revealed ambiguity attitude. The subjects' ambiguity attitudes were inferred by comparing their certainty equivalents in the risky and the ambiguous prospect games. As the difference between the two certainty equivalents gets larger, the stronger is the aversion to ambiguity. However this measure is scale dependent, and needs to be converted into a scale free measurement. We use the following scale free measure to capture ambiguity attitude.

\section{CE of Risky prospect-CE of ambiguous prospect \\ CE of Risky prospect + CE of ambiguous prospect}

This measure ranges from -1 (ambiguity loving) to 0 (ambiguity neutrality) to 1 (ambiguity averse). ${ }^{5}$ The normalization controls for the fact that a difference of $\$ 5$ may weigh more heavily for a subject who is very risk averse (e.g. certainty equivalent \$10) than for a subject who is relatively risk neutral (e.g. certainty equivalent \$20).

Although it is not the focus of our study, we also run a regression model to explain risk attitudes on trust, happiness and other covariates for purposes of comparison. We use subjects' risk premium (percentage) as a measure of risk attitude. The results of our random effects regression analysis are presented in Table 3.

\footnotetext{
${ }^{5}$ A CE of zero for the ambiguous prospect would yield an index value of 1, no differential between the CE of the risky and ambiguous prospects would yield a value of zero, and a CE of zero for risky prospects with any positive CE for ambiguous prospects would imply a value of -1 .
} 
Table 3: Regression analysis of risk and ambiguity attitudes (Random Effects Regression ${ }^{6}$ )

\begin{tabular}{|l|l|l|}
\hline Explanatory Variables & Risk Attitudes & Ambiguity Attitude \\
\hline Age & 0.046 & 0.043 \\
& $(0.053)$ & $(0.050)$ \\
\hline Male & 0.121 & 0.037 \\
& $(0.097)$ & $(0.077)$ \\
\hline Trust & 0.058 & $0.201 * * *$ \\
& $(0.057)$ & $(0.042)$ \\
\hline Happiness & 0.080 & 0.031 \\
& $(0.067)$ & $(0.044)$ \\
\hline Optimism (stated belief) & -0.003 & $-0.018 * * *$ \\
& $(0.004)$ & $(0.006)$ \\
\hline Constant & -0.587 & 0.283 \\
& $(1.013)$ & $(1.062)$ \\
\hline No of observations & 40 & 40 \\
\hline R2 & 0.20 & 0.48 \\
\hline
\end{tabular}

Notes: **, and *** denotes significance at 5 and $1 \%$ levels, respectively. Robust standard errors are in parenthesis.

Our regression results indicate that subjects' trust and happiness levels have significant impact on ambiguity aversion but not on risk attitudes. In particular, ambiguity aversion appears to be correlated with pessimism and a lack of trust. Unlike findings in the literature, we did not find any significant impact of gender and age on either risk or ambiguity aversion, though we note the limited variation in age in our sample.

\section{Conclusions}

Attitudes towards uncertainty with both known and unknown probabilities are important factors in the analysis of economic problems both in the developed and developing world. There is a growing literature on the use of experimental techniques to elicit risk and ambiguity aversion both on student and non-student subjects, and most of these studies have produced evidence

\footnotetext{
${ }^{6}$ We were unable to use subject fixed effect regression as our variable of interests (such as emotional parameters) are game-invariant.
} 
supporting the presence of ambiguity aversion. Most of these studies were conducted using a single probability interval and hence cannot help us to understand how subjects react when the probability intervals of ambiguity prospects change.

In this study, we analyze ambiguity (and risk) aversion among student subjects when the same subjects are confronted with two ambiguity games with equivalent expected outcomes but framed with different probability intervals, one relatively narrow and another relatively wider. Our findings indicate that ambiguity aversions depend on the probability interval (degree of ambiguity). Subjects are found to be more ambiguity averse to prospects with wide probability intervals than to an equivalent prospect with narrow intervals. While merely suggestive, another interesting finding is on the role of emotional parameters on ambiguity aversions. Our regression analysis indicates that subjects' inherent trust and level of optimism do affect the level of ambiguity aversions. Further research in neuroeconomics may be needed in order to gain deeper understanding of the mechanisms by which emotional factors are related to decisions under uncertainty. 


\section{References}

Alpizer, F., F. Carlsson, M. Naranjo, (2010). The effect of risk, ambiguity, and coordinationon farmers' adaptation to climate change: A framed field experiment. Working paper EfD, Gothenburg Universoty, Sweden.

Camerer, C., \& Weber, M. (1992). Recent developments in modeling preferences -uncertainty and ambiguity. Journal of Risk and Uncertainty, 5, 325-370.

Chow, Claire C. and Rakesh K. Sarin (2002). Known, Unknown, and Unknowable Uncertainties. Theory and Decision 52, $127 \cdot 138$.

Cohen, Michele., Jean-Yves Jaffray and Tanios Said (1985). Individual Behavior under Risk and Uncertainty: An Experimental Study. Theory and Decision 18, 203-328.

Dalton, T., and M. Yesuf (2011). Demand for drought tolerance in Africa: selection of drought tolerant maize seed using framed field experiment. Agricultural and applied economics association meeting, Pittesburg, Pennsylavania.

Ellsberg, D. (1961). Risk, ambiguity, and the Savage axioms. Quarterly Journal of Economics, $75,643-699$.

Fox, Craig R. and Amos Tversky (1995). Ambiguity Aversion and Comparative Ignorance. Quarterly Journal of Economics 110, 585-603.

Heath, Chip and Amos Tversky (1991). Preference and Belief: Ambiguity and Competence in Choice and Uncertainty. Journal of Risk and Uncertainty 4, 5-28.

Hogarth, Robin M. and Howard Kunreuther (1985). Ambiguity and Insurance Decisions. American Economic Review 75(2), 386 • 390.

Ritov, I., \& Baron, J. (1990). Reluctance to vaccinate: Omission bias and ambiguity. Journal of Behavioral Decision Making, 3, 263-277.

Viscusi, W. Kip and Harrell W. Chesson (1999). Hopes and fears: The conflicting effects of risk ambiguity. Theory and Decision 47, $153 \cdot 178$.

Viscusi, W. Kip and Wesley A. Magat (1992). Bayesian decisions with ambiguous beliefmaversion. Journal of Risk and Uncertainty 5, $371 \cdot 387$.

Viscusi, W. K., Magat, W. A., \& Huber, J. (1991). Communication of ambiguous risk information. Theory and Decision, 31, 159-173.

Zeckhauser, Richard J. (2006). Investing in the Unknown and Unknowable. Capitalism and Society 1, Article 5. 
Appendix: The full set of the experiment

Part I : Game 1

Player No.

Choice list on prospect 1 risk game ( $10 \%$ of winning $\$ 0 \& 90 \%$ of winning $\$ 40$ ):

\begin{tabular}{|lllll|}
\hline$[1]$ & Bet on prospect 1 & $\mathrm{O}$ & $\mathrm{O}$ & Receive $\$ 5$ for sure \\
\hline$[2]$ & Bet on prospect 1 & $\mathrm{O}$ & $\mathrm{O}$ & Receive $\$ 10$ for sure \\
\hline$[3]$ & Bet on prospect 1 & $\mathrm{O}$ & $\mathrm{O}$ & Receive $\$ 15$ for sure \\
\hline$[4]$ & Bet on prospect 1 & $\mathrm{O}$ & $\mathrm{O}$ & Receive $\$ 20$ for sure \\
\hline$[5]$ & Bet on prospect 1 & $\mathrm{O}$ & $\mathrm{O}$ & Receive $\$ 25$ for sure \\
\hline$[6]$ & Bet on prospect 1 & $\mathrm{O}$ & $\mathrm{O}$ & Receive $\$ 30$ for sure \\
\hline$[7]$ & Bet on prospect 1 & $\mathrm{O}$ & $\mathrm{O}$ & Receive $\$ 35$ for sure \\
\hline
\end{tabular}




\section{Part I : Game2}

Player No.

Choice list on prospect 1 ambiguity game (0-20\% of winning $\$ 0 \& 80-100 \%$ of winning $\$ 40$ ):

\begin{tabular}{|c|c|}
\hline [8] Bet on prospect 1 & Receive $\$ 5$ for sure \\
\hline [9] Bet on prospect 1 & Receive $\$ 10$ for sure \\
\hline [10] Bet on prospect 1 & Receive $\$ 15$ for sure \\
\hline [11] Bet on prospect 1 & Receive $\$ 20$ for sure \\
\hline [12] Bet on prospect 1 & Receive $\$ 25$ for sure \\
\hline [13] Bet on prospect 1 & Receive $\$ 30$ for sure \\
\hline [14] Bet on prospect 1 & Receive $\$ 35$ for sure \\
\hline
\end{tabular}

Follow up question:

What is your best guess of the probability of winning (put a number between 80 and 100\%) 
Part II : Game 1

Player No.

Choice list on prospect 2 risk game ( $25 \%$ of winning $\$ 0 \& 75 \%$ of winning $\$ 48)$ :

\begin{tabular}{|lllll|}
\hline$[15]$ & Bet on prospect 2 & $\mathrm{O}$ & $\mathrm{O}$ & Receive $\$ 5$ for sure \\
\hline$[16]$ & Bet on prospect 2 & $\mathrm{O}$ & $\mathrm{O}$ & Receive $\$ 10$ for sure \\
\hline$[17]$ & Bet on prospect 2 & $\mathrm{O}$ & $\mathrm{O}$ & Receive $\$ 15$ for sure \\
\hline$[18]$ & Bet on prospect 2 & $\mathrm{O}$ & $\mathrm{O}$ & Receive $\$ 20$ for sure \\
\hline$[19]$ & Bet on prospect 2 & $\mathrm{O}$ & $\mathrm{O}$ & Receive $\$ 25$ for sure \\
\hline$[20]$ & Bet on prospect 2 & $\mathrm{O}$ & $\mathrm{O}$ & Receive $\$ 30$ for sure \\
\hline$[21]$ & Bet on prospect 2 & $\mathrm{O}$ & $\mathrm{O}$ & Receive $\$ 35$ for sure \\
\hline
\end{tabular}


Part II : Game 2

Player No.

Choice list on prospect 2 ambiguity game (0-50\% of winning \$0 \& 50-100\% of winning \$48):

\begin{tabular}{|c|c|}
\hline [22] Bet on prospect 2 & Receive $\$ 5$ for sure \\
\hline [23] Bet on prospect 2 & Receive $\$ 10$ for sure \\
\hline [24] Bet on prospect 2 & Receive $\$ 15$ for sure \\
\hline [25] Bet on prospect 2 & Receive $\$ 20$ for sure \\
\hline [26] Bet on prospect 2 & Receive $\$ 25$ for sure \\
\hline [27] Bet on prospect 2 & Receive $\$ 30$ for sure \\
\hline [28] Bet on prospect 2 & Receive $\$ 35$ for sure \\
\hline
\end{tabular}

Follow up question:

What is your best guess of the probability of winning (put a number between 50 and 100\%) 